\title{
Research on Innovation and Entrepreneurship Education Serving Industrial Upgrading
}

\author{
Zhixia Zhou ${ }^{1, a}$ and Hongxuan Lv ${ }^{2, b}$ \\ ${ }^{1}$ Economy and Management Department, Weifang University, Weifang, China \\ ${ }^{2}$ Collection Integrated Services Section, Social Insurance Business Management Center,Weifang, \\ China \\ a13356711666@126.com, bwfxykxj@163.com
}

Keywords: Innovation and entrepreneurship education; Industrial upgrading; Utility mechanism; operation mechanism; Coordinated development

\begin{abstract}
Innovation and entrepreneurship is the root of national development and the soul of national rejuvenation. This thesis deeply explored the utility mechanism of innovation and entrepreneurship education serving the industrial upgrading, constructed operation mechanism of multi-agent collaborative innovation and entrepreneurship, based on theoretical analysis and practical research, it proposed serving mode and developing suggestions for innovation and entrepreneurship education to promote industrial transforming and upgrading.
\end{abstract}

\section{Introduction}

Innovation and entrepreneurship is the root of national development and national rejuvenation. In its "Opinions on vigorously promoting innovation and entrepreneurship in universities and undertaking entrepreneurship by undergraduates", the Education Ministry of China explicitly proposed that innovation and entrepreneurship education was the new educational concept and model. National Medium and Long-Term (2010-2020) Education Reform and Development Plan pointed out that higher education should strengthen the practice of teaching and promote entrepreneurship education. With economic development entering a new normal stage, structural contradictions in higher education have become more prominent and homogeneity tendencies have become more serious. The structure and quality of personnel training haven't met the requirements of industrial restructuring and upgrading. How to adapt innovation and entrepreneurship education in colleges and universities to the requirements of industrial restructuring and economic development and to realize the dynamic mechanism transformation of industrial upgrading under the "new normal" stage, is a major issue we should study and discuss.

\section{Research on Innovation and Entrepreneurship Education with Industrial Development}

(1) Innovation and entrepreneurship education theory and development practice

The United States is the earliest country of innovation and entrepreneurship education. It has gone through more than 60 years of history and theoretical research and practice have taken the lead in the world. In 1947, Harvard Business School's "Start-up Management” course, pioneered by Professor MvlesMace, was widely considered by most entrepreneurs as the first college start-up course in the United States, a hallmark of entrepreneurial education in the origins of American colleges and universities. Until now, there has been a prairie fire in the entrepreneurial boom of college students all over the world. Entrepreneurship and innovation and entrepreneurship education are also highly valued by all countries. Since the 1990s, besides the United States and Britain, Japan, India, Singapore, Australia and other countries have taken innovation and entrepreneurship education as a strategy to train challenging personnel for the future and vigorously implemented the innovation and entrepreneurship education program. Domestic scholars such as Zhaoxin Huang, Xiaohui Yang, Zhanren Wang and Yuanxu Li studied the innovation and entrepreneurship education 
reform paths and patterns[1][2]. Jian Zhu, Maoxin Yan, Zhanren Wang, Chenglong Xue and other scholars further explored relationship between entrepreneurship ecosystem and entrepreneurship education in colleges and universities[3][4].

(2) Innovation and entrepreneurship education theory and regional economic development

Empirical studies by American scholar Bluestone (1993) and Ferran Mane (1999) find that the development of higher education can serve the development of regional economy. In 2006, the Institute of Regional Forecasting at the University of Houston proposed that high quality higher education was one of the prerequisites for the regional economic diversification and future economic stability and prosperity. John Naisbitt argued that entrepreneurship was the basis for the continued prosperity of the United States economy. Peter Drucker, a guru in management, pointed out that entrepreneurial employment was one of the main engines of economic development in the United States. Researches from GEM also proved the service function of entrepreneurial activity to economic growth. Domestic scholars such as Shengli Cao, an assistant to president of China Association of Higher Education, and Jiatao Lei, the deputy director of China Entrepreneurship Research Center at Tsinghua University, believed that innovation and entrepreneurship education in colleges and universities could interact with regional social-economic development through three levels: basic level, practical level and safeguard level[5]. Yang Cao, Zhenghai Yao, and Xiaosu Chen explored the relationship between innovation and entrepreneurship training and economic development mode, regional industrial layout and advantages[6].

\section{Utility and Operating Mechanism of Innovation and Entrepreneurship Education}

\section{(1) Utility mechanism of innovation and entrepreneurship education serving industrial upgrading}

Based on the domestic and international theoretical research and practice, this study argues that innovation and entrepreneurship education in colleges and universities can serve regional industrial upgrading through the following ways: innovation and entrepreneurship intellectual resources provide intellectual output for industrial development, innovation and entrepreneurial talent resources provide adaptability high-level talent output, innovation and entrepreneurial cultural resources provide social innovation and entrepreneurship value concept and cultural atmosphere.

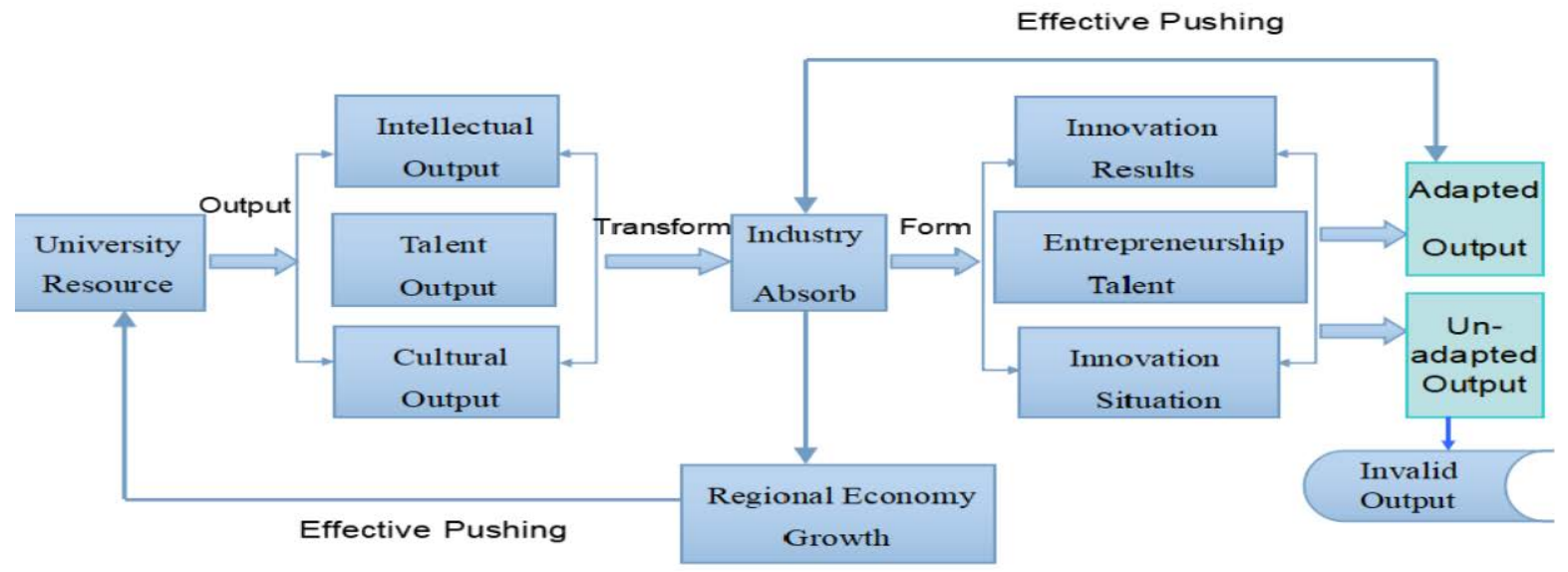

Fig.1. Utility mechanism of innovation and entrepreneurship education serving industrial upgrading

As shown in Fig.1, the utility mechanism of innovation and entrepreneurship education to promote industrial upgrading is as follows: Outcomes of intellectual property, talent and cultural achievements of universities in exporting innovation and entrepreneurship education are absorbed by relevant industries after they are transformed, then forms scientific and technological innovation that boosts the industrial upgrade, innovates the pioneering talents and creates the culture of 
innovation and entrepreneurship so as to serve the regional economic development.

\section{(2) Operate mechanism of innovation and entrepreneurship education serving industrial upgrading}

Based on the deep analysis of utility mechanism of innovation and entrepreneurship education serving industrial upgrading, this theses constructed the operation mechanism of innovation and entrepreneurship education serving industrial upgrading (as shown in Fig.2). In the process of innovation and entrepreneurship education in colleges and universities and the development of regional industry transformation, the achievements of innovation and entrepreneurship education and the performance of industry development form an interactive system of mutual coupling.

First of all, the reform of university's own innovation and entrepreneurship arouses the need of multi-agent collaborative innovation and entrepreneurship, and leads universities to export the resources of inovation and entrepreneurship to the multi-agent platform. Secondly, the mechanism of interest-based cooperation with multi-agent collaborative innovation and entrepreneurship platform as a center gave play the synergistic effects, and provide intellectual achievement, talent achievement and cultural achievement. Finally, the innovation and entrepreneurial achievements are transformed and applied in specific industries,the performance evaluation mechanism ensures the sound performance of collaborative innovation and entrepreneurship, so as to form a dynamic ecosystem with good matching between educational achievements and industrial needs.

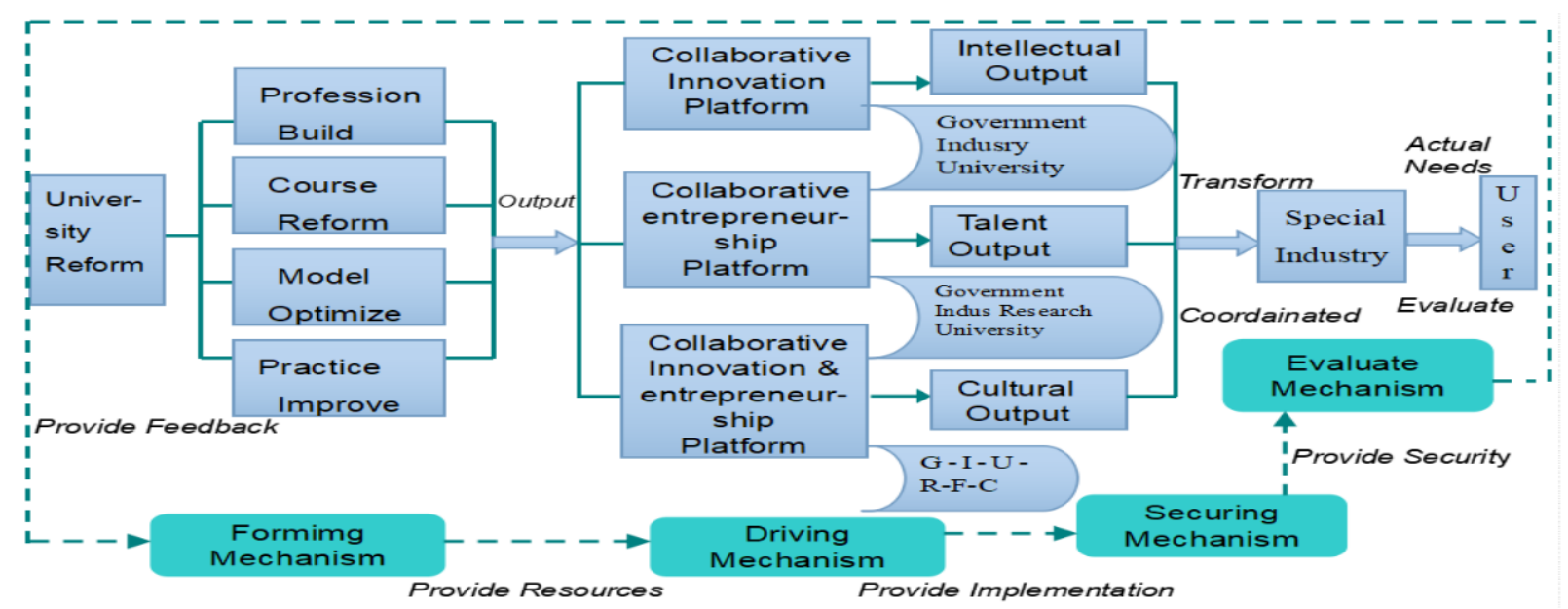

Fig.2. Operate mechanism of innovation and entrepreneurship education serving industrial upgrading

a. Collaborative innovation and entrepreneurship forming mechanism. The innovation and entrepreneurship education reform in colleges and universities has led to the formation of innovation and entrepreneurship operation mechanism, including the innovation and entrepreneurship education, reform of curriculum system, optimization of training mode and improvement of practice system.

b. Collaborative innovation and entrepreneurial driving mechanism. The operation of the innovation and entrepreneurship mechanism is driven by the interest-based mechanism centered on multi-agent synergistic innovation and entrepreneurship platform, which integrates resources of innovation and entrepreneurship in politics, industry, research, and commerce to further develop the synergy utility of $1+1>3$.

c. Collaborative innovation and entrepreneurship protecting mechanism. The securing bodies are constructed by the government, research intermediaries, and financial institutions, providing policy, capital, technology and other multi-party security to innovation and entrepreneurship education.

d. Collaborative innovation and entrepreneurship evaluating mechanism. The relevant industry enterprises and end-users are regarded as the main body of evaluation, which evaluates the input of education resources for innovation and entrepreneurship, the performance of multi-agent collaborative innovation and entrepreneurship, education and industrial fitness. The evaluation 
results form a feedback mechanism and further promote the innovation and entrepreneurship education reform in colleges and universities.

\section{Mode choice and Path Recommendations for Innovation and Entrepreneurship Education}

\section{(1) To implement “double creation” education and form “cross-border synergy" model}

First of all, we should integrate the teachers and students' needs in the innovation and entrepreneurship education, colleges and universities should be based on students' needs to do selection and construction of the tutor group. Secondly, universities and government departments should do a good policy docking, colleges and universities must take the main responsibility, and explore the effective ways of innovation and entrepreneurship education. Thirdly, we should do the collaborative choice between colleges and universities, industries, enterprises, markets and capital. We should choose the collaborative environment of innovation and entrepreneurship education based on the market environment so as to effectively integrate the intelligence, information and economic resources of universities, research institutions, industries and enterprises, thus cultivate the market needs of innovative entrepreneurship.

(2) To improve the driving mechanism and strengthen innovation and entrepreneurship system security

Firstly, we should continuously improve the synergistic driving mechanism of innovation and entrepreneurship so as to ensure a common consensus among all cross-boundary parties. Secondly, we should continue to improve the drive mechanism of innovation and entrepreneurship sharing. Any benefit-sharing needs to achieve the goal of cultivating entrepreneurship talents first, all parties involved in the cooperation should carry out the scientific and reasonable sharing of benefits. Thirdly, the driving mechanism of innovation and entrepreneurship should be further improved. In the practice of innovation and entrepreneurship education, special attention should be paid to safeguarding the original features and existing consensus on development of innovation and entrepreneurship education in colleges and universities, so as to improve talent diversification and applicability.

(3) To integrate into industrial development and adapt to industrial restructuring and upgrading

On the one hand, universities should integrate the concept of innovation and entrepreneurship education into the local industrial development. They should devote themselves to providing talent support and intellectual support for the transformation and upgrading of local industries and economic and social development. We should persist in serving the development of strategic emerging industries as an application to schools, focus on building a cooperation framework of “industry - strategic alliance - professional group - practice base”, "business center - research and innovation platform - technology center', on building scientific research and innovation platform, thus can serve the universities education directly into regional development, industrial revitalization and technological progress, and promote the application and innovation of advanced technology.

On the other hand, the innovation and entrepreneurship education system in colleges and universities should adapt to the industrial restructuring and upgrading. Colleges and universities should actively improve the innovation and entrepreneurship education system, set up an innovation and entrepreneurship education platform and establish a practice incubation and practice platform. At the same time, colleges and universities should cultivate talents with a liberal free academic environment and an effective platform for innovation and entrepreneurship, and promote student-centered innovative experimental teaching. In addition, we should establish an employer-oriented feedback mechanism for the industry to effectively meet the needs of qualified personnel for industrial restructuring and upgrading.

\section{Conclusion}

How to adapt the innovation and entrepreneurship education in colleges and universities to the 
requirements of industrial restructuring and economic development, how to realize the dynamic mechanism transformation of industrial restructuring and upgrading under the "new normal" stage, is an urgent issue to be solved in the innovation and entrepreneurship education. Based on theoretical analysis and practical research,we suggested that, colleges and universities should implement the innovation and entrepreneurship education, gradually form the "cross-border synergy"development model, improve the driving mechanism to strengthen the system security of innovation and entrepreneurship, and integrate education into industrial development, thus can make the education better adapted to and helpful for industrial restructuring and upgrading.

\section{Acknowledgement}

In this paper, the research was sponsored by Ministry of Education Collaborative Education Project (Project No. 201702068055), Shandong Province Human \& Social Science Program (Project No. 17-ND-JJ-15), Ministry of Education Industry-University Cooperation Collaborative Education Project (Project No. 201602028046).

\section{References}

[1] Chen Xiaochu. College Students Innovation and Entrepreneurship Education[J]. China Higher Education, 201514 (4) 75-81.

[2] Yan Jianhua. Construction of Innovation-Based Entrepreneurship Education[J]. Chinese Higher Education, 201612 (7) 39-43.

[3] Zeng Li, Zhang Zhongqiu, Liu Yannan. Innovation and Entrepreneurship Education in Colleges and Universities Need to Cooperate with Each Other[J]. Educational Research, 20177 (1) 54-59.

[4] Hao Jie. American Innovation and Entrepreneurship Education System Construction and Enlightenment[J]. Higher Engineering Education Research, 20165 (4) 82-86.

[5] Wang Zhanren. Study on the Disciplinary Characteristics and Development Orientation of Innovative Entrepreneurship Education in Chinese Higher Education[J]. Educational Research,2016 13 (6) 29-35.

[6] Xue Chenglong. Review of Higher Education Innovation and Entrepreneurship Education in the 12th Five-Year Plan[J]. China Higher Education Research, 20165 (2) 97-103. 